\section{Genetic interaction between Wnt/ $\beta$-catenin and BMP receptor signaling during formation of the AER and the dorsal-ventral axis in the limb}

\author{
Natalia Soshnikova, ${ }^{1}$ Dietmar Zechner, ${ }^{1}$ \\ Joerg Huelsken, ${ }^{1,5}$ Yuji Mishina, ${ }^{2,6}$ \\ Richard R. Behringer, ${ }^{2}$ Makoto M. Taketo, ${ }^{3}$ \\ E. Bryan Crenshaw III, ${ }^{4}$ and Walter Birchmeier ${ }^{1,7}$ \\ ${ }^{1}$ Max-Delbrück-Centrum for Molecular Medicine, \\ Robert-Rössle-Straße 10, 13125 Berlin, Germany; ${ }^{2}$ Department \\ of Molecular Genetics, University of Texas M.D. Anderson \\ Cancer Center, Houston, Texas 77030, USA; ${ }^{3}$ Department of \\ Pharmacology, Kyoto University Graduate School of \\ Medicine, Yoshida-Konoe-cho, Sakyo-ku, Kyoto 606-8501, \\ Japan; ${ }^{4}$ Mammalian Neurogenetics Group, Center for \\ Childhood Communication, Children's Hospital of \\ Philadelphia, Philadelphia, Pennsylvania 19104, USA
}

By conditional gene ablation in mice, we found that $\beta$-catenin, an essential downstream effector of canonical Wnt signaling, is a key regulator of formation of the apical ectodermal ridge (AER) and of the dorsal-ventral axis of the limbs. By generation of compound mutants, we also show that $\beta$-catenin acts downstream of the BMP receptor IA in AER induction, but upstream or parallel in dorsal-ventral patterning. Thus, AER formation and dorsal-ventral patterning of limbs are tightly controlled by an intricate interplay between Wnt/ $\beta$-catenin and BMP receptor signaling.

Received May 14, 2002; revised version accepted June 6, 2003.

Significant progress has been achieved in the understanding of the molecular networks that control limb development (for review, see Capdevila and Izpizua Belmonte 2001; Niswander 2003). Three cardinal axes are established in the developing limb by coordinated interactions between distinct signaling centers; that is, the apical ectodermal ridge (AER) that controls proximaldistal elongation, the zone of polarizing activity (ZPA) that is responsible for anterior-posterior patterning, and the ectoderm of the limb bud that directs dorsal-ventral axis formation.

Wnt molecules are important regulators in diverse developmental processes, and control cell proliferation, differentiation, and survival (Wodarz and Nusse 1998; East-

[Keywords: Limb ventral ectoderm; proximal-distal axis; FGF; Engrailed-1; Frizzled]

Present addresses: ${ }^{5}$ ISREC, Chemin des Boveresses 155, Lausanne, Switzerland; ' ${ }^{6}$ aboratory of Reproductive and Developmental Toxicology, National Institute of Environmental Health Sciences, Research Triangle Park, North Carolina 27709, USA.

${ }^{7}$ Corresponding author.

E-MAIL wbirch@mdc-berlin.de; FAX 49-30-94062656

Article and publication are at http://www.genesdev.org/cgi/doi/10.1101/ gad.263003. man and Grosschedl 1999; Huelsken and Birchmeier 2001). Wnt ligands signal through different receptors of the Frizzled and LRP families and result in the stabilization of $\beta$-catenin, a central and essential component of the canonical Wnt-signaling pathway. $\beta$-Catenin then interacts with LEF/TCF transcription factors to control the expression of specific target genes (Behrens et al. 1996; Eastman and Grosschedl 1999; van de Wetering et al. 2002). In the absence of Wnt signals, the $\mathrm{N}$ terminus of $\beta$-catenin is phosphorylated by CKI and GSK3 $\beta$, and phosphorylated $\beta$-catenin is subsequently ubiquitinated and degraded (Schwarz-Romond et al. 2002, and references therein). Mutations in tumors that affect these $\mathrm{N}$ terminal phosphorylation sites lead to a stabilization of $\beta$-catenin and enhanced signaling activity (Polakis 2000).

Wnt signals participate in the patterning of limb (Capdevila and Izpizua Belmonte 2001). In the chick embryo, limb formation is initiated by Wnt-2b and Wnt-8c, which are expressed in the lateral plate mesoderm at the forelimb and hindlimb level, respectively, and signal through $\beta$-catenin to restrict the expression of Fgf-10 to the prospective limb mesoderm (Kawakami et al. 2001). FGF-10 then induces the expression of Wnt-3a in the limb ectoderm that is required for Fgf8 expression in the presumptive AER (Grieshammer et al. 1996; Kengaku et al. 1998; Kawakami et al. 2001; McQueeney et al. 2002). It was shown recently that the closely related Wnt3 takes over this function in the mouse (Barrow et al. 2003). Independent confirmation for such a mechanism was provided by the analysis of Lef-1/Tcf-1 mutant mice that lack Fgf8 expression in the limb ectoderm and do not form an AER (Galceran et al. 1999). Wnt-7a, which signals via a $\beta$-catenin independent pathway, is crucial for the dorsal-ventral patterning (Parr and McMahon 1995). Wnt-7a expression is restricted to the dorsal ectoderm by En-1, which is essential for ventral cell fate specification (Loomis et al. 1996).

Not only Wnts, but also BMP signals are important in AER formation and in dorsal-ventral patterning. Conditional inactivation of the Bmp receptor IA in mice impairs both AER formation and dorsal-ventral patterning of limb, and affects the expression of Fgf8 and En-1 (Ahn et al. 2001). In the chick, expression of a constitutively active BMP receptor causes ectopic expression of Fgf8 and En-1 (Pizette et al. 2001). BMP signals regulate the development of many tissues and organs, and extensive interactions between BMP and Wnt-signaling pathways have been reported (Kratochwil et al. 1996; Theil et al. 2002). However, the hierarchies of $\mathrm{Wnt} / \beta$-catenin and BMP signaling pathways have not been established in the limb, and it is unclear whether Wnts and BMPs control consecutive or parallel events during the formation of dorsal-ventral and proximal-distal axes in the limb.

To elucidate the interaction between Wnt/ $\beta$-catenin and BMP signals during limb formation by genetic means, we have used the Cre-lox $P$ technology to ablate $\beta$-catenin and to express stabilized $\beta$-catenin in the ectoderm of the hindlimb. Loss of $\beta$-catenin results in defects in both AER formation and dorsal-ventral patterning, which are similar to those observed after ablation of the $B m p$ receptor $I A$. Moreover, we establish the epistatic relation of $\mathrm{Wnt} / \beta$-catenin and $\mathrm{BMP}$ receptor IA using double mutants, and thus uncover an intricate interaction of the two pathways. 
Soshnikova et al.

\section{Results and Discussion}

\section{$\beta$-Catenin is essential for limb development}

We used two distinct mutant alleles to introduce lossof-function and gain-of-function mutations into the mouse $\beta$-catenin gene. The first allele contains two lox $P$ sites that flank exons 3-6 ( $\beta$-cat $\left.{ }^{\text {flox }}\right)$; upon recombination, no $\beta$-catenin protein is produced, and the recombined allele thus corresponds to a null mutation (Huelsken et al. 2001). The second allele contains two lox $P$ sites that flank exon $3(\Delta N-\beta$-cat $)$; after Cre-induced deletion of exon 3 , stabilized $\beta$-catenin protein is produced that cannot be phosphorylated (Harada et al. 1999). To introduce conditional mutations into the $\beta$-catenin locus, a transgene that expresses Cre under the control of the Brn4 neural tube enhancer/promoter was used (Ahn et al. 2001; Heydemann et al. 2001). Cre activity was assessed with the help of a lacZ indicator strain. Brn4Cre-mediated recombination of a lac Z reporter gene was observed in limb-bud ectoderm (Fig. 1A; Ahn et al.

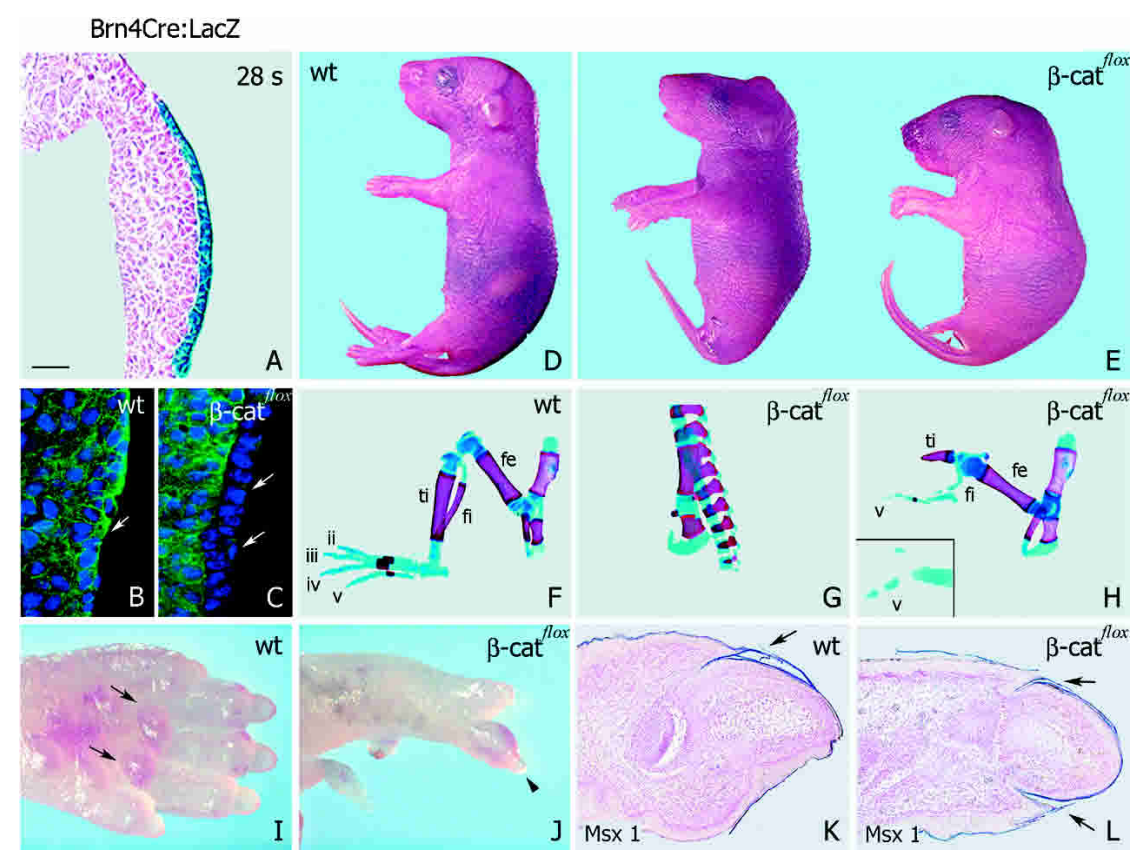

Figure 1. Conditional ablation of $\beta$-catenin inhibits hindlimb development. $(A)$ Section along the dorsal-ventral axis of hindlimb of Brn4Cre; lacZ embryos. Cre activity is restricted to limb ectoderm. $(B, C)$ Analysis of $\beta$-catenin expression in wild-type and severely affected Brn 4 Cre; $\beta$-catenin ${ }^{\text {flox/flox }}$ hindlimbs. $\beta$-Catenin is absent in the ventral ectoderm of mutants, as detected by immunofluorescence ( $\beta$-catenin is indicated in green, DAPI nuclei staining in blue). Arrows mark the surface ectoderm. $(D, E)$ Lossof-function mutation of $\beta$-catenin in the limb ectoderm results in variable hindlimb deformations. $(F-H)$ Skeletal preparations of hindlimbs of wild-type and mutant mice. The malformation of mutant hindlimbs (70 animals were examined) consists of truncation at the proximal femur $(G, 50 \%)$, disgenesis of tibia and fibula, and loss of digits $1-4(H, 11 \%)$. The distal element of digit $\mathrm{V}$ is often bifurcated (inset in $H, 83 \%)$. $(I, J)$ Gross morphology of wild-type and Brn4Cre; $\beta$-catenin ${ }^{\text {flox/flox }}$ autopods (ventral view). Autopods of newborn mutant mice are dorsalized, as dermal pads (arrows) are absent on the ventral surface of mutant paws, and nails are circumferential (arrowhead). $(K, L)$ Sagittal sections of wild-type and mutant digits, demonstrating nail plates on dorsal and ventral surfaces in the mutants (arrows), as indicated by in situ hybridization for Msx1. $(A-C, K, L)$ Dorsal is to the top. (fe) Femur; (fi) fibula; (ti) tibia. Bars: $A, 40 \mu \mathrm{m} ; B, C$, $50 \mu \mathrm{m} ; D, E, 3 \mathrm{~mm} ; F-H, 1 \mathrm{~mm} ; I, J, 0.5 \mathrm{~mm} ; K, L, 100 \mu \mathrm{m}$.
2001) and in the central nervous system (Zechner et $\beta$-catenin was absent in the ventral ectoderm of the 作 $\beta$-catenin in dorsal ectoderm occurred later than in ventral ectoderm, and was observed at the 40 -somite stage (data not shown). We also observed heterogeneity in the bryos (see below).

Brn4Cre-induced loss-of-function mutation of $\beta$ catenin Bulted in severe malformations of the hindlimbs (Fig. 1D-L). In strongly affected individuals, the hindlimbs were completely lacking (Fig. 1E,G). Others disdigits I-IV (Fig. 1E of tibia and fibula, and an absence of only digit II and/or III were missing (data not shown). Moreover, in hindlimbs of mildly affected mutants the ventral dermal pads were absent, and circumferential nails were detected (Fig. 1I,J). Histological examination showed that nail plates were present on both dorsal and ventral surfaces of mutant hindlimbs (Fig. 1K,L). Thus, mutant mice displayed an absence of ventral and a duplication of dorsal structures. Forelimbs of mutants displayed rarely minor anatomical changes. This is consistent with low and late activity of Cre in the forelimb ectoderm of Brn4Cre embryos (data not shown; Ahn et al. 2001). The complete absence or the severe malformations of the hindlimb of Brn4Cre; $\beta$-catenin ${ }^{\text {flox/flox }}$ mutant mice indicate that $\beta$-catenin plays an essential role during early stages of limb development.

\section{$\beta$-Catenin acts downstream of $B M P$ receptor IA during AER formation}

The severe truncations of limb along the proximal-distal axis in $\beta$-catenin loss-of-function mutants suggest a deficit in AER formation. To address this, the expression of genes in the hindlimb AER were analyzed in $\beta$-catenin gain- and loss-of-function embryos. In the loss-of-function mutants, Fgf8, Bmp2, and Bmp4 were completely absent in strongly affected embryos at the 38-42-somite stage (data not shown). A few remaining Fgf 8 and Bmp4-positive spots of cells were located at the distal rim and also at ectopic ventral positions in mildly affected animals (Figs. 2A,B, 3A-D; data not shown). Serial sections indicate that remaining Fgf8- or Bmp4-expressing cells were $\beta$-catenin positive (Fig. $2 \mathrm{D}, \mathrm{E}$; data not shown). In gain-of-function mutants, Fgf8, Bmp2, and Bmp4 expression domains in the hindlimb 

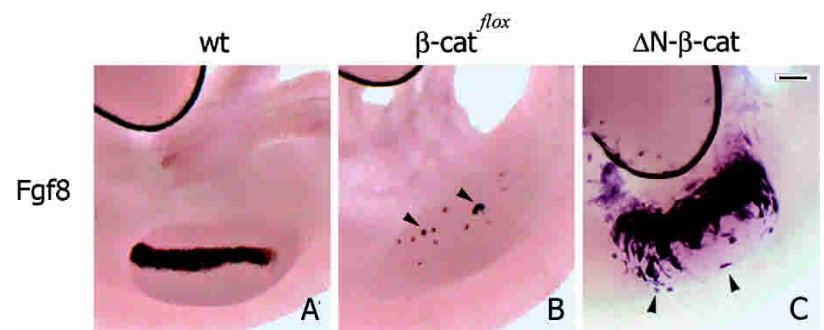

$\beta-$ cat
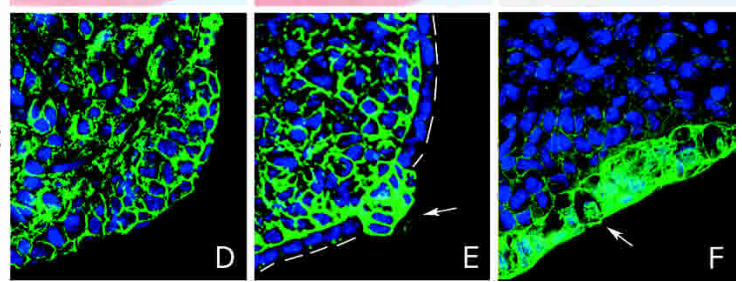

Figure 2. $\beta$-Catenin is essential for AER formation. $(A, B)$ Reduction of Fgf8 expression in hindlimbs of mutants carrying loss-of-function mutation of $\beta$-catenin, in comparison with wild type, at the 38-42-somite stage (arrowheads). (C) Strong ventrally expanded expression domain of $F g f 8$ in mutants harboring the gain-of-function mutation of $\beta$-catenin. Note ectopic expression of $F g f 8$ in dorsal limb ectoderm (arrowheads). $(D, E)$ Expression of $\beta$-catenin in spots, but not in the surrounding ectoderm of mildly affected mutants carrying loss-of-function mutation of $\beta$-catenin, as detected by immunofluorescence at the $38-42$-somite stage ( $\beta$-catenin is indicated in green, DAPI nuclei staining in blue; the surface of the ectoderm is marked by a broken line). Note that the exposition time was reduced in $F$. Bars: $A-C, 150 \mu \mathrm{m} ; D-F, 15 \mu \mathrm{m}$.

bud were markedly expanded (Figs. 2C, 3E,F; data not shown), and strong expression of $\beta$-catenin was observed in the cytoplasm and the nucleus of AER cells (Fig. 2F, arrow shows nuclear staining). Moreover, a clearly discernable AER was either absent or strongly reduced in size in loss-of-function mutants (Figs. 2E, 3C,D). In contrast, a dramatically expanded AER was observed in gainof-function mutants (Figs. 2, cf. C and A, 3, cf. E,F and $A, B)$. We conclude that $\beta$-catenin is essential for the expression of AER-specific genes and for AER formation, and that it acts in a cell-autonomous manner.

Brn4Cre-induced loss-of-function mutation of the $B m p$ receptor IA results in AER deficits that are very similar to those we observed in Brn4Cre; $\beta$-catenin ${ }^{\text {flox/flox }}$ mutants (Ahn et al. 2001). For instance, the expression of Fgf8 and Bmp4 was absent or severely reduced, and the formation of the AER was impaired in Bmp receptor $I A$ loss-of-function mutants (Fig. 3G,H). This raises the question of whether the $\beta$-catenin and BMP receptor IA pathways interact during AER formation. To address this, we generated compound mutants, that is, embryos that carry a gain-of-function mutation in $\beta$-catenin and a loss-of-function mutation of the Bmp receptor IA in the hindlimb ectoderm (Brn4Cre $; \Delta N-\beta$-catenin:BmpRIA flox/flox $)$. Remarkably, these compound mutants expressed Fgf8 and $B m p 4$ strongly in the ventral ectoderm prior to AER formation (at the 30-somite stage; data not shown). At subsequent stages (for instance at the 42-somite stage), the area of the AER, the expression domains of Fgf8 and $B m p 4$, and the overall size of the limb were strongly enlarged in the compound mutants (Fig. 3I,J); this was also observed in embryos that carry only the $\beta$-catenin gain-of-function mutation (cf. Fig. 3E,F). We conclude from these results that increased $\beta$-catenin signaling can rescue the deficits in AER formation caused by loss-offunction mutation of the $B m p$ receptor $I A$. We can thus position $\beta$-catenin-mediated signaling to act genetically downstream of BMP receptor IA during formation of the AER (see scheme in Fig. 3, right). Moreover, expression of $B m p 4$, a ligand of the BMP receptor IA, is controlled by $\beta$-catenin signals, and is enhanced in compound and in $\beta$-catenin gain-of-function mutants. $\beta$-Catenin therefore also participates in a positive feedback loop that amplifies BMP signaling.

To address the question of how BMP receptor IA signaling may control Wnt/ $\beta$-catenin signaling in AER formation, we examined in Bmp receptor IA loss-of-function mutants, the expression of genes of canonical Wnt signaling. Expression of Wnt3, which is essential for AER formation (Barrow et al. 2003), was not changed in the ectoderm of mutant limbs (Fig. 4A,B). Fzd6 and Fzd8 were also present in both dorsal and ventral limb ecto-

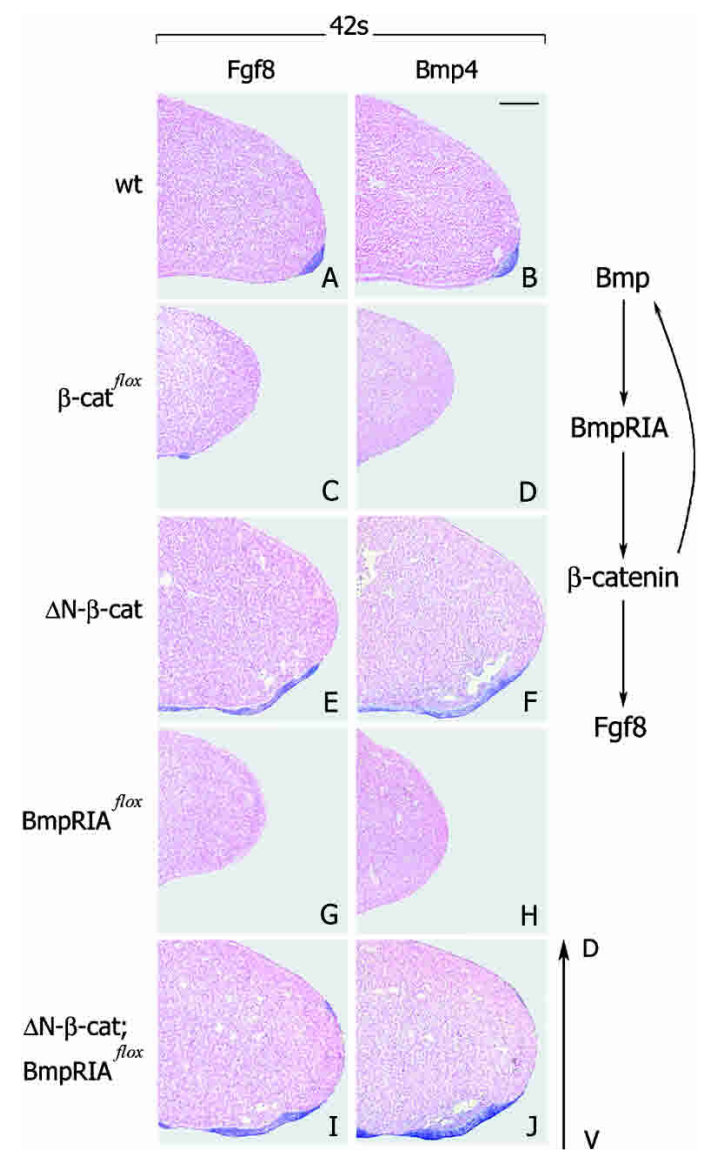

Figure 3. $\beta$-Catenin acts downstream of the BMP receptor IA during AER formation (see scheme at right). $(A-D)$ AER is absent or only few groups of cells resembling AER are present in $\beta$-catenin loss-of-function mutant limbs at the 42 -somite stage. $(E, F)$ AER and overall size of limb are strongly enlarged in $\beta$-catenin gain-of-function mutants at the 42-somite stage. $(G, H)$ AER is not formed in Bmp receptor IA loss-of-function mutants at the 42 -somite stage. $(I, J)$ Limbs are strongly enlarged and the AER is expanded to ventral side in compound mutants at the 42-somite stage (cf. E,F). Dorsal ventral is as indicated. Bar, $100 \mu \mathrm{m}$. 
Soshnikova et al.

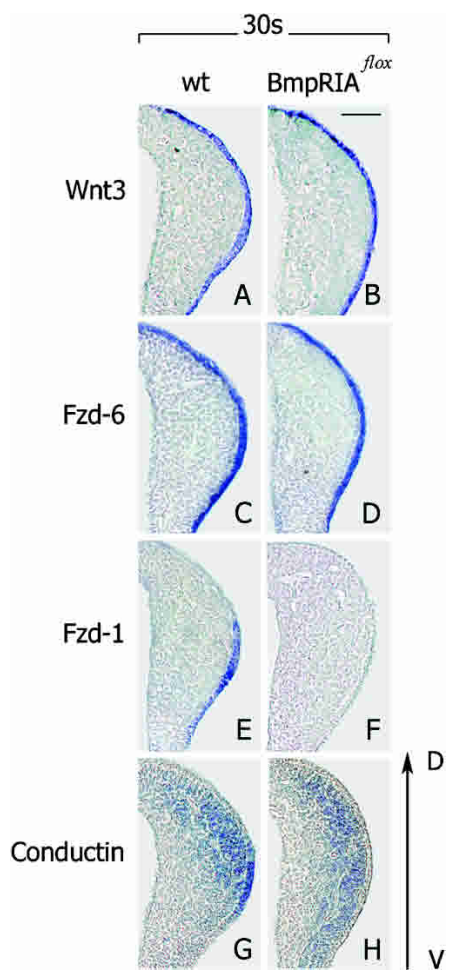

Figure 4. $\beta$-Catenin signaling depends on BMP receptor signaling during AER formation. $(A-D)$ Expression of Wnt3 and Fzd6 are not changed in the limb ectoderm of $B m p$ receptor IA lossof-function mutants at the 30 -somite stage. $(E-H) F z d 1$ and conductin are not expressed in ventral ectoderm of $B m p$ receptor $I A$ loss-of-function mutants at the 30 -somite stage. Note that conductin expression was analyzed in compound mice expressing $l a c Z$ under the control of the conductin promoter. Dorsal ventral is as indicated. Bar, $50 \mu \mathrm{m}$.

derm in Bmp receptor IA mutants (Fig. 4C,D; data not shown). In contrast, Fzd1 expression was detected in the ventral ectoderm of control embryos, but not of Bmp receptor IA loss-of-function mutants (Fig. 4E,F, at the 26-31-somite stage). However, Fzd1 was present in $\beta$-catenin loss-of-function mutants (data not shown), indicating that BMP receptor IA, but not $\beta$-catenin signaling, is required for expression of this gene. In Bmp receptor IA loss-of-function mutants, we also examined the expression of a direct target gene of $\mathrm{Wnt} / \beta$-catenin signaling, conductin (Jho et al. 2002; Lustig et al. 2002), using mice that carry a lacZ gene in the conductin locus. Expression of conductin was absent in the limb ectoderm of the Bmp receptor IA mutants (Fig. 4G,H). These data confirm that Wnt/ $\beta$-catenin signaling is located downstream of BMP receptor signaling during induction of the AER, and that Fzdl might be a crucial component in this cross-talk.

$\beta$-Catenin acts upstream of, or in parallel with, the $B M P$ receptor IA during specification of the dorsal-ventral axis

Brn4Cre-induced loss-of-function mutation of $\beta$-catenin resulted in the absence of ventral and in the duplication of dorsal structures, which indicates a defect in dorsal- ventral patterning (Fig. 1I-L). The expression of En-1 in the ventral limb ectoderm was absent (Fig. 5C), and the expression domain of Wnt-7a was expanded into the ventral ectoderm of $\beta$-catenin mutants (Fig. 5, cf. D and controls in $\mathrm{A}, \mathrm{B}$; arrows indicate the borders of expression). $L m x 1 b$ was expressed only in the dorsal half of the limb mesenchyme in control mice, and its expression expanded into the ventral domain of the mutant limb bud (data not shown; Riddle et al. 1995). The expression pattern of En-1 and Wnt-7a was not changed in the $\beta$-catenin gain-of-function mutants (Fig. $5 \mathrm{E}, \mathrm{F}$ ); note that Brn4Cre is only active in the ventral ectoderm. BMP receptor IA signaling was also required for correct dorsalventral patterning of the limb and for correct expression

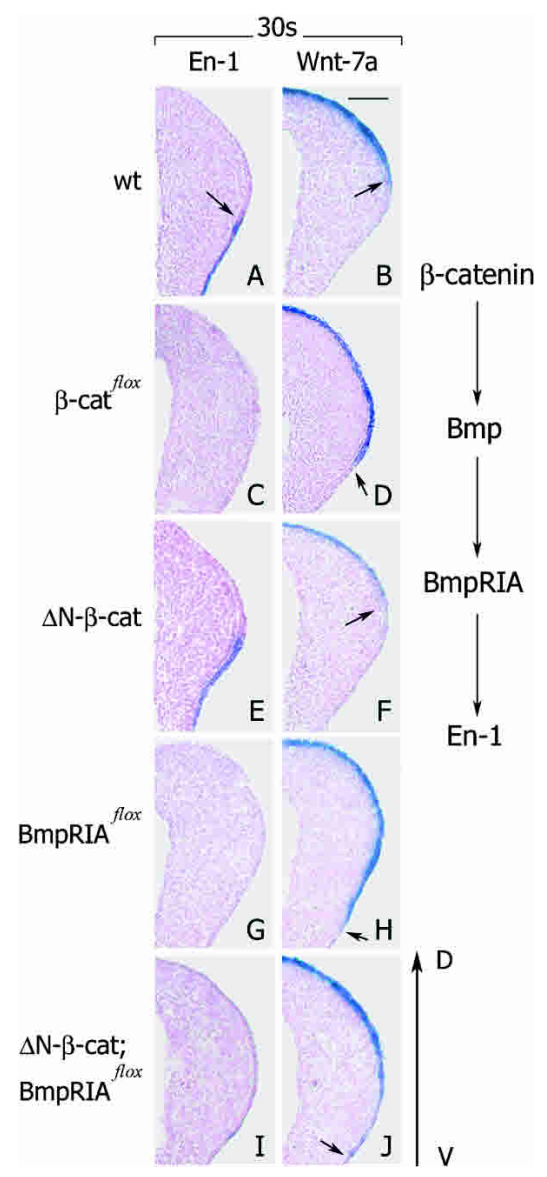

Figure 5. $\beta$-Catenin acts upstream of, or in parallel to, the BMP receptor IA during dorsal-ventral patterning of limbs (see scheme at right). $(A, C)$ En-1 is not expressed in ventral limb ectoderm of mutants carrying loss-of-function mutation of $\beta$-catenin at the 30 -somite stage. $(B, D) W n t-7 a$ is expressed ectopically in ventral ectoderm of $\beta$-catenin loss-of-function mutant limbs at the 30-somite stage. $(E, F) E n-1$ and Wnt-7a expression domains in $\beta$-catenin gain-of-function mutants resemble the wild type. $(G) E n-1$ is not expressed in ventral ectoderm of mutants carrying the loss-of-function mutations of Bmp receptor IA. (H) Wnt-7a is expressed in both dorsal and ventral ectoderm in mutants carrying loss-of-function mutation of $B m p$ receptor IA. (I) En-1 is not expressed in the ventral ectoderm of compound mutants at the 30 -somite stage. (J) Wnt-7a is expressed in ventral limb ectoderm of compound mutants at the 30 -somite stage (cf. $H$ ). Dorsal ventral is as indicated. Bar, $50 \mu \mathrm{m}$. 
of En-1 and Wnt-7a (Fig. 5G,H; see also Ahn et al. 2001). To establish the epistatic interaction between $\beta$-catenin and BMP receptor IA signaling in dorsal-ventral patterning, we examined compound mutant embryos that carried a gain-of-function mutation of $\beta$-catenin and a loss-offunction mutation of the Bmp receptor IA for the expression of En-1 and Wnt-7a. Remarkably, in the compound mutants, En-1 expression in the ventral ectoderm was absent (Fig. 5I), and Wnt-7a was expressed in both dorsal and ventral ectoderm (Fig. 5J, arrow). Thus, both ectodermal $\beta$-catenin and BMP receptor IA are required for correct specification of the ventral character in limb ectoderm. However, enhanced $\beta$-catenin signaling does not rescue the deficits caused by Bmp receptor IA loss-of-function mutation, suggesting that genetically, $\beta$-catenin acts upstream or in parallel to the BMP receptor IA during dorsal-ventral patterning (see scheme in Fig. 5, right).

It is known that the Wnt/ $\beta$-catenin and TGF $\beta / B M P$ signaling pathways coordinately govern many developmental processes. During limb development, Wnt and BMP signals control the formation of the AER and participate in the establishment of the dorsal-ventral axis (Ahn et al. 2001; Pizzete et al. 2001; Barrow et al. 2003; this study). The interactions between the two signaling systems in the limb were, however, not understood, and the epistatic relationship between BMP and Wnt signals remained unclear. Here, we have analyzed the interactions between Wnt/ $\beta$-catenin and BMP receptor signaling during limb development using conditional mutagenesis, which allowed us to introduce loss-of-function and gain-of-function mutations of $\beta$-catenin, the central and essential mediator of canonical Wnt signaling. In addition, we generated compound mutant mice that carry both a gain-of-function mutation in $\beta$-catenin and loss-of-function mutations in Bmp receptor IA. Our analysis of these compound Brn4Cre; $\Delta N-\beta$-catenin: $B m p R I A^{\text {flox/flox }}$ mutant mice clearly demonstrates that $\beta$-catenin acts downstream of the BMP receptor IA in AER induction. $\beta$-Catenin-mediated signals do, however, control Bmp4 expression in the ectoderm, and are thus responsible for the formation of a positive feedback loop. In contrast, our data suggest that $\beta$-catenin acts upstream or in parallel to the BMP receptor IA during dorsal-ventral patterning. These intricate interactions between the Wnt/ $\beta$-catenin and BMP-signaling pathways provide the molecular basis that connects the development of proximal-distal and dorsal-ventral axes in the limb, and might thus ensure a tight spatial-temporal control of signaling responses.

After submission of this manuscript, a publication appeared that demonstrated that Wnt3/ $\beta$-catenin-transmitted signals in the ventral limb ectoderm are essential for AER induction and maintenance as well as for the dorsal-ventral polarity, and it was suggested that Wnt $3 / \beta$ catenin signaling acts upstream of BMP signaling in both AER formation and dorsal-ventral polarity (Barrow et al. 2003). These data are in agreement with ours with respect to the role of $\beta$-catenin in AER formation and dorsal-ventral patterning. However, they disagree with ours on the epistatic relationship between Wnt/ $\beta$-catenin and BMP signaling.

\section{Material and methods}

Mouse strains and embryos

$\beta$-Catenin flox mice, $\beta$-catenin ${ }^{\text {lox }(e x 3)}$ mice, BmpRIA flox mice, and Brn4Cre transgenic mice (pedigree bcre-32) were described previously
(Harada et al. 1999; Ahn et al. 2001; Huelsken et al. 2001; Mishina et al. 2002). To obtain loss-of-function mutations of $\beta$-catenin in the limb ectoderm, homozygous mice carrying $\beta$-catenin ${ }^{\text {flox }}$ alleles were crossed with Brn4Cre transgenic mice that were heterozygous for the $\beta$-catenin $^{\text {flox }}$ allele. To obtain the gain-of-function mutation of $\beta$-catenin in the limb ectoderm, heterozygous mice carrying the $\beta$-catenin ${ }^{\text {lox(ex3) }}$ allele were crossed with Brn4Cre transgenic mice. To obtain loss-offunction mutations of $B m p R I A$, homozygous mice carrying $B m p R I A^{\text {flox }}$ alleles were crossed with Brn4Cre mice that were heterozygous for the $B m p R I A^{\text {flox }}$ allele. To obtain compound mutant embryos, heterozygous mice carrying the $\beta$-catenin ${ }^{\operatorname{lox}(\operatorname{ex} 3)}$ gain-of-function allele and the $B m p R I A^{f l o x}$ loss-of-function allele were crossed with Brn4Cre transgenic mice that were heterozygous for the $B m p R I A^{\text {flox }}$ allele. Heterozygous mice carrying the conductin ${ }^{+/ l a c Z}$ allele (Lustig et al. 2002) and the $B m p R I A^{\text {flox }}$ loss-of-function allele were crossed with Brn4Cre transgenic mice that were heterozygous for the $B m p R I A^{\text {flox }}$ allele. Mutant embryos were identified by PCR (Harada et al. 1999; Ahn et al. 2001; Huelsken et al. 2001; Lustig et al. 2002). Cre-inducible lacZ reporter mice were described previously (Thorey et al. 1998).

Histological techniques and in situ hybridization

Wild-type and mutant embryos $(n \geq 5)$ were age-matched according to their somite numbers, and fixed in $4 \%$ formaldehyde in PBS. Immunohistochemical analyses were performed on 5 - $\mu \mathrm{m}$ paraffin sections as described previously (Hulsken et al. 1994). Skeletons of newborn pups were prepared and stained with Alcian blue 8GX and Alizarin red S as described (Hogan et al. 1994).

In situ hybridization of whole-mount or paraffin sections was performed using digoxygenin-labeled (DIG) RNA probes (Roche; see Huelsken et al. 2000). The anti-sense transcripts of mouse cDNAs were as follows: Bmp4 (nucleotides 290-1780, X56848), En-1 (nucleotides 1041-1741, NM010133), Fgf8 (Crossley and Martin 1995), Fzd1 (IMAGp952G2216), Fzd6 (IRAKp961C2218), Msx1 (Hill et al. 1989), Wnt3 (nucleotides 300-1120, NM009521), and Wnt-7a (ICRFp522L0361). The DIG label was detected by an anti-DIG Fab (Roche) coupled to alkaline phosphatase, using NBT/BCIP (Sigma).

\section{Acknowledgments}

We thank C. Birchmeier for helpful discussions and critical reading of the manuscript. We also thank C. Birchmeier, G. Martin, and L. Niswander for in situ probes. The study was supported by the Volkswagen Stiftung and the Deutsche Forschungsgemeinschaft (Sonderforschungsbereich 366).

The publication costs of this article were defrayed in part by payment of page charges. This article must therefore be hereby marked "advertisement" in accordance with 18 USC section 1734 solely to indicate this fact.

\section{References}

Ahn, K., Mishina, Y., Hanks, M.C., Behringer, R.R., and Crenshaw III, E.B. 2001. BMPR-IA signaling is required for the formation of the apical ectodermal ridge and dorsal-ventral patterning of the limb. Development 128: 4449-4461.

Barrow, J.R., Thomas, K.R., Boussadia-Zahui, O., Moore, R., Kemler, R., Capecchi, M.R., and McMahon, A.P. 2003. Ectodermal Wnt3/ $\beta$ catenin signaling is required for the establishment and maintenance of the apical ectodermal ridge. Genes \& Dev. 17: 394-409.

Behrens, J., von Kries, J.P., Kuhl, M., Bruhn, L., Wedlich, D., Grosschedl, R., and Birchmeier, W. 1996. Functional interaction of $\beta$-catenin with the transcription factor LEF-1. Nature 382: 638-642.

Capdevila, J. and Izpisua Belmonte, J.C. 2001. Patterning mechanisms controlling vertebrate limb development. Annu. Rev. Cell. Dev. Biol. 17: $87-132$.

Crossley, P.H. and Martin, G.R. 1995. The mouse Fgf8 gene encodes a family of polypeptides and is expressed in regions that direct outgrowth and patterning in the developing embryo. Development 121: 439-451.

Eastman, Q. and Grosschedl, R. 1999. Regulation of LEF-1/TCF tran scription factors by Wnt and other signals. Curr. Opin. Cell. Biol. 11: $233-240$.

Galceran, J., Farinas, I., Depew, M.J., Clevers, H., and Grosschedl, R. 1999. Wnt3a $\mathrm{a}^{-/-}$-like phenotype and limb deficiency in Lef1(-)Tcf1(-/-) mice. Genes \& Dev. 13: 709-717. 
Grieshammer, U., Minowada, G., Pisenti, J.M., Abbott, U.K., and Martin, G.R. 1996. The chick limbless mutation causes abnormalities in limb bud dorsal-ventral patterning: Implications for the mechanism of apical ridge formation. Development 122: 3851-3861.

Harada, N., Tamai, Y., Ishikawa, T., Sauer, B., Takaku, K., Oshima, M., and Taketo, M.M. 1999. Intestinal polyposis in mice with a dominant stable mutation of the $\beta$-catenin gene. EMBO J. 18: 5931-5942.

Heydemann, A., Nguyen, L.-C., and Crenshaw III, E.B. 2001. A regulatory region of the Brn4/Pou $3 \mathrm{f} 4$ promoter directs expression to developing forebrain and neural tube. Dev. Brain Res. 128: 83-90.

Hill, R.E., Jones, P.F., Rees, A.R., Sime, C.M., Justice, M.J., Copeland, N.G., Jenkins, N.A., Graham, E., and Davidson, D.R. 1989. A new family of mouse homeo box-containing genes: Molecular structure, chromosomal location, and developmental expression of Hox-7.1. Genes \& Dev. 3: 26-37.

Hogan, B.L., Beddington, R., Costantini, F., and Lacy, E. 1994. Manipulating the mouse embryo. Second ed. pp. 381-383. Cold Spring Harbor Laboratory Press, Cold Spring Harbor, NY.

Huelsken, J. and Birchmeier, W. 2001. New aspects of Wnt signaling pathways in higher vertebrates. Curr. Opin. Genet. Dev. 11: 547-553.

Huelsken, J., Vogel, R., Erdmann, B., Cotsarelis, G., and Birchmeier, W. 2001. $\beta$-catenin controls hair follicle morphogenesis and stem cell differentiation in the skin. Cell 105: 533-545.

Hulsken, J., Birchmeier, W., and Behrens, J. 1994. E-cadherin and APC compete for the interaction with $\beta$-catenin and the cytoskeleton. $J$. Cell. Biol. 127: 2061-2069.

Jho E.H., Zhang, T., Domon, C., Joo, C.K., Freund, J.N., and Costantini, F. 2002. Wnt/ $\beta$-catenin/Tcf signaling induces the transcription of Axin2, a negative regulator of the signaling pathway. Mol. Cell. Biol. 22: $1172-1183$.

Kawakami, Y., Capdevila, J., Buscher, D., Itoh, T., Rodriguez, E.C., and Izpisua Belmonte, J.C. 2001. WNT signals control FGF-dependent limb initiation and AER induction in the chick embryo. Cell 104: 891-900.

Kengaku, M., Capdevila, J., Rodriguez-Esteban, C., De La Peña, J., Johnson, R.L., Belmonte, J.C., and Tabin, C.J. 1998. Distinct WNT pathways regulating AER formation and dorsoventral polarity in the chick limb bud. Science 280: 1274-1277.

Kratochwil, K., Dull, M., Farinas, I., Galceran, J., and Grosschedl, R. 1996. Lef1 expression is activated by BMP-4 and regulates inductive tissue interactions in tooth and hair development. Genes \& Dev. 10: 1382-1394.

Loomis, C.A., Harris, E., Michaud, J., Wurst, W., Hanks, M., and Joyner, A.L. 1996. The mouse Engrailed-1 gene and ventral limb patterning. Nature 382: 360-363.

Lustig, B., Jerchow, B., Sachs, M., Weiler, S., Pietsch, T., Karsten, U., van de Wetering, M., Clevers, H., Schlag, P.M., Birchmeier, W., et al. 2002. Negative feedback loop of Wnt signaling through upregulation of conductin/axin2 in colorectal and liver tumors. Mol. Cell. Biol. 22: $1184-1193$.

McQueeney, K., Soufer, R., and Dealy, C.N. 2002. $\beta$-catenin-dependent Wnt signaling in apical ectodermal ridge induction and FGF8 expression in normal and limbless mutant chick limbs. Dev. Growth Differ. 44: 315-325.

Mishina, Y., Hanks, M.C., Miura, S., Tallquist, M.D., and Behringer, R.R. 2002. Generation of Bmpr/Alk3 conditional knockout mice. Genesis 32: $69-72$.

Niswander, L. 2003. Pattern formation: Old models out on a limb. Nat. Rev. Genet. 4: 133-143.

Parr, B.A. and McMahon, A.P. 1995. Dorsalizing signal Wnt-7a required for normal polarity of D-V and A-P axes of mouse limb. Nature 374: 350-353.

Pizette, S., Abate-Shen, C., and Niswander, L. 2001. BMP controls proximodistal outgrowth, via induction of the apical ectodermal ridge, and dorsoventral patterning in the vertebrate limb. Development 128: 4463-4474.

Polakis, P. 2000. Wnt signaling and cancer. Genes \& Dev. 14: 1837-1851.

Riddle, R.D., Ensini, M., Nelson, C., Tsuchida, T., Jessell, T.M., and Tabin, C. 1995. Induction of the LIM homeobox gene Lmxl by WNT7a establishes dorsoventral pattern in the vertebrate limb. Cell 83: 631-640.

Schwarz-Romond, T., Asbrand, C., Bakkers, J., Kuhl, M., Schaeffer, H.J., Huelsken, J., Behrens, J., Hammerschmidt, M., and Birchmeier, W.
2002. The ankyrin repeat protein Diversin recruits Casein kinase I $\varepsilon$ to the $\beta$-catenin degradation complex and acts in both canonical Wnt and Wnt/JNK signaling. Genes \& Dev. 16: 2073-2084.

Theil, T., Aydin, S., Koch, S., Grotewold, L., and Ruther, U. 2002. Wnt and Bmp signalling cooperatively regulate graded Emx2 expression in the dorsal telencephalon. Development 129: 3045-3054.

Thorey, I.S., Muth, K., Russ, A.P., Otte, J., Reffelmann, A., and von Melchner, H. 1998. Selective disruption of genes transiently induced in differentiating mouse embryonic stem cells by using gene trap mutagenesis and site-specific recombination. Mol. Cell. Biol. 18: 3081-3088.

van de Wetering, M., Sancho, E., Verweij, C., de Lau, W., Oving, I., Hurlstone, A., van der Horn, K., Batlle, E., Coudreuse, D., Haramis, A.P., et al. 2002. The $\beta$-catenin/TCF-4 complex imposes a crypt progenitor phenotype on colorectal cancer cells. Cell 111: 241-250.

Wodarz, A. and Nusse, R. 1998. Mechanisms of WNT signalling in development. Annu. Rev. Dev. Biol. 14: 59-88.

Zechner, D., Fujita, Y., Hülsken, J., Müller, T., Walther, I., Taketo, M.M., Crenshaw, E.B., Birchmeier, W., and Birchmeier, C. 2003. $\beta$-Catenin signals regulate cell growth and the balance between progenitor cell expansion and differentiation in the nervous system. Dev. Biol. 258: 406-418. 


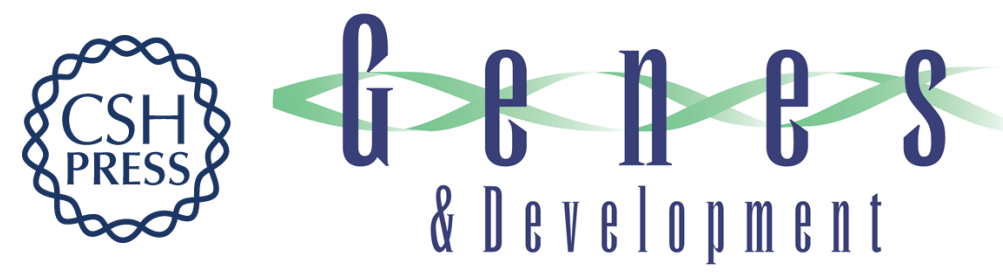

\section{Genetic interaction between Wnt/ $\beta$-catenin and BMP receptor signaling during formation of the AER and the dorsal-ventral axis in the limb}

Natalia Soshnikova, Dietmar Zechner, Joerg Huelsken, et al.

Genes Dev. 2003, 17:

Access the most recent version at doi:10.1101/gad.263003

References This article cites 31 articles, 15 of which can be accessed free at:

http://genesdev.cshlp.org/content/17/16/1963.full.html\#ref-list-1

License

Email Alerting Receive free email alerts when new articles cite this article - sign up in the box at the top Service right corner of the article or click here.

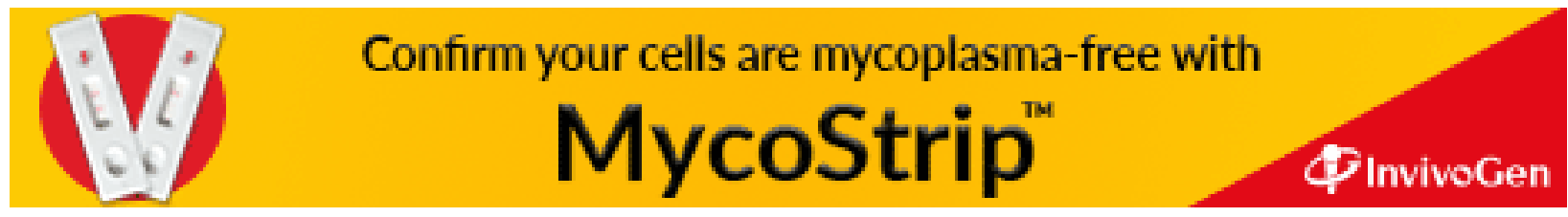

